\title{
The carbon dioxide marginal abatement cost calculation of Chinese provinces based on stochastic frontier analysis
}

\author{
Kejia Yang $^{1,2} \cdot$ Yalin Lei $^{1,2}$
}

Received: 18 March 2016/Accepted: 2 September 2016/Published online: 22 September 2016

(C) The Author(s) 2016. This article is published with open access at Springerlink.com

\begin{abstract}
The Chinese government made a commitment to achieve a 40-45\% reduction in carbon emissions per unit of gross domestic product (GDP) by 2020 compared with 2005. Most provinces followed the national commitment due to unified task of 40-45\% reduction in carbon emissions. However, different industrial structures, energy consumption structures and natural resources endowment of each province vary the emission abatement costs. Each province should take the carbon dioxide abatement cost into consideration for the carbon dioxide reduction target. Data envelopment analysis (DEA) and linear programming (LP) methods were used to measure the marginal abatement cost in previous studies. In this paper, we built a quadratic parametric directional distance function (DDF) to measure the carbon dioxide marginal abatement cost of Chinese provinces. To overcome the flaw of ignoring random errors in previous research, this paper compared results of stochastic frontier analysis (SFA) method and DEA method. Because DEA method only considers the inefficiency and SFA method can distinguish the random error from inefficiency, the result of the average carbon dioxide marginal abatement cost of each province calculated by SFA was $55 \%$ lower than DEA method. As the random error may be introduced by chosen function form, Spearman test and paired sample $\mathrm{T}$ test were used to test the correlation of two methods' MAC results. The results show that the ranking order MAC results sequence of SFA method and DEA method is highly correlated. But the MAC value of SFA and DEA methods has significant difference. As half of the error comes from the random error, the MAC results calculated by SFA method are more precise than DEA method. So SFA method is more appropriate than DEA in this paper. This result reinforces the feasibility of the Chinese government carbon dioxide emission reduction target. However, this study proved that the carbon dioxide emissions and marginal
\end{abstract}

Yalin Lei

leiyalin@cugb.edu.cn

1 School of Humanities and Economic Management, China University of Geosciences, Beijing 100083, China

2 Key Laboratory of Carrying Capacity Assessment for Resource and Environment, Ministry of Land and Resources, Beijing 100083, China 
abatement cost varied from province to province. Furthermore, there was no distinct correlation between carbon dioxide emissions and the marginal abatement cost. On the contrary, the marginal abatement cost was related to the industrial structures, energy consumption structures and natural resources endowment of each province. Therefore, two policy suggestions are proposed as $\mathrm{CO}_{2}$ emission reduction principle: First, central government should establish $\mathrm{CO}_{2}$ emission reduction targets based on MAC and local economic affordability. Second, resource endowments and embodied carbon transfer should be considered.

Keywords Carbon dioxide - Marginal abatement cost - Directional distance function . Stochastic frontier analysis · Policy suggestions

\section{Introduction}

The rapid development of the Chinese economy caused a large amount of carbon dioxide $\left(\mathrm{CO}_{2}\right)$ emissions. The $\mathrm{CO}_{2}$ emissions of China increased quickly since 2000 (Song 2010; Guo et al. 2010), as the proportion of Chinese $\mathrm{CO}_{2}$ emissions in the global emissions increased from $12.9 \%$ in 2000 to approximately $23 \%$ in 2010 (China Electricity Council 2011; Qi et al. 2014). According to a scientific forecast, the proportion will drastically increase to one-third of the global emissions if no effective $\mathrm{CO}_{2}$ emission restriction is imposed in China (Liao and Wei 2011). Facing both the awareness of environmental protection and the international pressure on $\mathrm{CO}_{2}$ emission reduction, the Chinese government made a commitment to achieve a 40-45\% reduction in carbon emissions per unit of GDP by 2020 compared with 2005 in the Climate Conference in Copenhagen in 2009 (China.com 2009). Lacking the central government's differentiation carbon dioxide reduction allocation, most provinces follow the national commitment. However, the industrial structure, energy consumption structure and natural resources of each province vary. Hence, it is not appropriate for all provinces ${ }^{1}$ to impose identical $\mathrm{CO}_{2}$ emission reduction criterion. To address this issue, previous studies researched the $\mathrm{CO}_{2}$ emission abatement costs of China as a whole, as well as in individual Chinese provinces. Policy suggestions were also proposed by these studies.

The related studies about Chinese $\mathrm{CO}_{2}$ abatement cost can be divided into two aspects: the marginal abatement cost (MAC) and macro-abatement cost (Wang et al. 2007; Fan et al. 2010; $\mathrm{Xu}$ and Dong 2011; Chang 2014). The $\mathrm{CO}_{2} \mathrm{MAC}$, also called the $\mathrm{CO}_{2}$ shadow price, is defined as the decrement amount of GDP when reduced to the last unit of $\mathrm{CO}_{2}$ emissions in a certain abatement technology status (Fan 2011; Chen 2010; Matsushita and Yamane 2012). The $\mathrm{CO}_{2}$ macro-abatement costs are defined as the decrement of GDP when imposing $\mathrm{CO}_{2}$ emission reduction measures in a certain period (Wang et al. 2007, Fan et al. 2010, $\mathrm{Xu}$ and Dong 2011). The MAC can express the difficulty of $\mathrm{CO}_{2}$ reduction more directly than the macro-abatement cost.

The directional distance function (DDF) was widely used in previous studies to calculate the $\mathrm{CO}_{2}$ MAC. However, the different forms of the DDF model will lead to different calculation results. In addition, the two methods commonly used by previous studies to solve DDF, data envelopment analysis (DEA) and linear programming (LP), have flaws.

\footnotetext{
${ }^{1}$ Beijing, Tianjin, Shanghai and Chongqing are municipalities.
} 
The DEA method cannot deal with random errors and wrap them into inefficiency terms. Besides, the DEA method can only be applied when the distance function is differentiate everywhere. Moreover, the different frontier of production function and direction vector of the DEA method will lead to different $\mathrm{CO}_{2}$ MAC results. The LP method does not take the measuring errors and approximation errors into consideration. Therefore, the calculated results of the $\mathrm{CO}_{2}$ reduction cost varied in previous studies.

The DDF, followed by the stochastic frontier analysis (SFA) method, is able to differentiate between random noise and inefficiency; therefore, it was used to accurately measure the $\mathrm{CO}_{2} \mathrm{MAC}$ of Chinese provinces in this paper. In this paper, we used DDF and SFA method to overcome the flaw of ignoring random errors and approximation errors. And the calculation of marginal abatement cost of Chinese provinces in this paper contributed to proposing the policy suggestions.

This paper is organized as follows. Section 2 introduces the literature review of carbon dioxide abatement costs. Section 3 describes the model and method. Section 4 constructs the direction distance model and stochastic frontier analysis. The conclusion and policy suggestions are given in Sect. 5 .

\section{Literature review}

The existing studies showed that a multitude of quantitative models were used to measure the $\mathrm{CO}_{2} \mathrm{MAC}$.

\subsection{Distance function}

The existing studies showed that distance function model, especially parametric DDF model, was the most widely used model in $\mathrm{CO}_{2}$ MAC. The Shephard output distance function was used by Lee (2005) and Rezek and Campbell (2007) to measure the American power station's MAC of sulfur dioxide, nitrogen dioxide, carbon dioxide and mercury. Hailu and Veeman (2000) then used Shephard output distance function to measure the Canadian paper industry's sulfur dioxide MAC. Lee and Zhang (2012) used input distance function to measure Chinese manufacturing industries' MAC. Wang and Wei (2014) used output distance function to measure $\mathrm{CO}_{2} \mathrm{MAC}$ of energy sectors of 30 Chinese provinces.

The DDF was applied in many fields of MAC. (Färe et al. 2005) measured the MACs of sulfur dioxide and carbon dioxide of 209 American power facilities. Matsushita and Yamane (2012) measured the $\mathrm{CO}_{2}$ and low-level radioactive waste MACs of the Japanese electric power sector. Gómez-Calvet et al. (2014) measured the MAC of undesirable output in 25 European countries. Molinos-Senante et al. (2015) measured the MAC of Spanish wastewater treatment plants. Wang et al. (2014a) measured the MACs of total nitrogen, total phosphorus and chemical oxygen demand in the Chinese agriculture industry. In addition, previous studies measured the $\mathrm{CO}_{2}$ MACs of the industrial sectors of China and Chinese provinces using the DDF (e.g., Chen 2010; Qin et al. 2011; Wen and Wu 2011; Wang et al. 2011a; Yuan et al. 2012; Chen 2013; Zhou et al. 2015).

Specifically, the $\mathrm{CO}_{2}$ MACs of Chinese provinces were calculated by previous studies. Wang et al. (2011b) measured the $\mathrm{CO}_{2}$ MACs of 28 provinces in 2007 by nonparametric DDF and DEA methods. Liu et al. (2011) measured the $\mathrm{CO}_{2} \mathrm{MACs}$ of 30 provinces from 2005 to 2007 by nonparametric DF and DEA methods. Huang and Wei (2012) measured the $\mathrm{CO}_{2}$ MACs of 29 provinces from 1995 to 2007 by DDF and LP methods. Zhang et al. 
Table 1 Comparison of the estimated $\mathrm{CO}_{2}$ MACs of Chinese provinces

\begin{tabular}{llll}
\hline Studies & Method & Sample & MAC (yuan/ton) \\
\hline (Wang et al. 2011a, b) & DDF/DEA & 28 provinces, 2007 & 475 \\
Liu et al. (2011) & DF/DEA & 30 provinces, 2005-2007 & 1739 \\
Huang and Wei (2012) & DDF/LP & 29 provinces, 1995-2007 & 1128 \\
Zhang et al. (2014) & DDF/LP & 29 provinces, 2006-2010 & 80.19 \\
He (2015) & DF/LP & 29 provinces, 2000-2009 & 104 \\
\hline
\end{tabular}

(2014) measured the $\mathrm{CO}_{2}$ MACs of 30 provinces from 2006 to 2010 using DDF and LP methods. He (2015) measured the $\mathrm{CO}_{2}$ MACs of 29 provinces from 2000 to 2009 using DF and LP methods. Due to the different methods and samples, the $\mathrm{CO}_{2} \mathrm{MAC}$ results varied (see Table 1).

\subsection{Other models}

The marginal cost curve model, vector autoregression (VAR) model and MARKAL model are commonly used in $\mathrm{CO}_{2} \mathrm{MAC}$ calculation. The marginal cost curve model was used by Li et al. (2010), Garg et al. (2014) and Wang et al. (2014b) to measure the $\mathrm{CO}_{2} \mathrm{MACs}$ of China, India and the Chinese energy sector, respectively. Ba and $\mathrm{Wu}$ (2010) and $\mathrm{Xu}$ and Lin (2015) used the VAR model to measure the $\mathrm{CO}_{2}$ MACs of China and the Chinese transportation sector, respectively. The MARKAL model and the MARKAL-MACRO model were used to measure the $\mathrm{CO}_{2}$ MACs of China and Taiwan's energy sectors(Chen 2005; Chen et al. 2007; Ko et al. 2010).

\subsection{Comments on the literature}

All of the above-mentioned models have room for improvement. Although the marginal cost curve model is simple in computation, the form of the cost curve will lead to a fitting error. The GDP was treated as the input in the VAR model and MARKAL model, while the distance function model considered the GDP as the output. Therefore, the GDP and $\mathrm{CO}_{2}$ emission could be treated equally in the distance function model. Hence, the distance function model was more suitable, as the MAC had close relationship with economic loss.

The parametric distance function and nonparametric distance function were two popular methods used to measure $\mathrm{CO}_{2}$ MACs (Liu et al. 2011). The parametric distance function needs to pre-establish a function which is different everywhere, while a specific function is not needed in the nonparametric distance function. The parametric distance function can be manipulated algebraically (Choi et al. 2012). In the 1970s, the Shephard output distance function was first used to measure the MACs of pollutants (Shephard 1970). The desirable and undesirable outputs were changed in the same ratio in the Shephard output distance function (Tu 2009; Dou and Li 2012; Chen 2011). However, in the reality, we want to increase the desirable output while decreasing undesirable output. The DDF which was proposed by Chambers et al. (1996) and (Färe et al. 1993) can achieve what reality requires. Besides, the directional distance function is invariant to affine data transformation under variable returns to scale (Aparicio et al. 2016).

The DEA and LP methods are usually used to solve the distance function. However, the DEA method can only be applied when the function is differentiable everywhere. Moreover, DEA method cannot deal with random errors and wrap it into inefficiency term (Lee 
et al. 2002; Vardanyan and Noh 2006). Although the LP method can guarantee that the function is differentiable everywhere, the statistic noise will affect the results prominently, when particular points are ignored in the LP method (Zhang and Choi 2014; Zhou et al. 2010). Hence, both the DEA and LP methods have flaws.

To measure the MAC more precisely, the DDF and SFA were used in this paper to overcome DEA and LP defects. SFA method is included to overcome the flaw of ignoring random errors. Moreover, the SFA has a translation property, which can consider the influence of statistical noise on the model (Du and Mao 2015).

\section{Model and Method}

The DDF model measuring the MAC of undesirable output was proposed by Chambers et al. (1996) and (Färe et al. 1993) separately. The DDF depicts an input-output process with multiple inputs and outputs based on production function. Then, a production possibility curve (PPC) in the two-dimensional space was built. However, the PPC boundary optimal cannot be touched as the restriction of technology. Hence, the MAC can be measured by the distance between the output set and PPC boundary.

\subsection{Establishment of DDF}

In a certain Chinese province, we considered a production process that employs three inputs: capital $\left(X_{\mathrm{k}}\right)$, labor $\left(X_{\mathrm{L}}\right)$ and energy $\left(X_{\mathrm{E}}\right)$, one desirable output GDP $(y)$ and one undesirable output $\mathrm{CO}_{2}$ emission $(b)$. The production technology set $P$ can be defined as:

$$
P=\{(y, b): X \text { can produce }(y, b)\}
$$

The set has the following properties:

(1) Inputs are free disposability: The increase in inputs will lead to increased output, that is to say, if $x^{\prime} \geq x$, then $P\left(x^{\prime}\right) \supseteq P(x)$.

(2) Weak disposability of undesirable outputs: The proportionate reduction of desirable and undesirable outputs simultaneously is possible with the given inputs; in other words, $(y, b) \in P, 0 \leq \theta \leq 1$, then $(\theta y, \theta b) \in P$.

(3) Free disposability of desirable: The desirable output reduction is possible with the given inputs and undesirable output, so, $(y, b) \in P, y^{\prime} \leq y$, then $\left(y^{\prime}, b\right) \in P$.

(4) Null-jointness: The desirable output must be accompanied by the generation of undesirable, and the only way to avoid desirable and undesirable outputs is to stop all production activities, which means $(y, b) \in P$, and $b=0$, then $y=0$.

Let $g=\left(g_{y}, g_{b}\right)$ as the directional vector which indicates the expansion of GDP in the direction of $g_{y}$ and the reduction of $\mathrm{CO}_{2}$ in the direction of $\mathrm{g}_{\mathrm{b}}$, then the DDF can be defined as:

$$
\vec{D}(X, y, b ; g)=\sup \left\{\beta:\left(y+\beta g_{y}, b-\beta g_{c}\right) \in P\right.
$$

where $\beta$ represents the maximum proportion of expansion or reduction. $\beta=0$ when the decision-making unit lies on the production frontier.

Figure 1 shows the schematic diagram of the DDF and the MAC of $\mathrm{CO}_{2}$ emission.

Point A stands for a certain region in the production technology set $P$, while coordinate axis $y$ and axis $b$ represent the GDP and $\mathrm{CO}_{2}$ emission in this region, respectively. A moves 
Fig. 1 Directional distance function

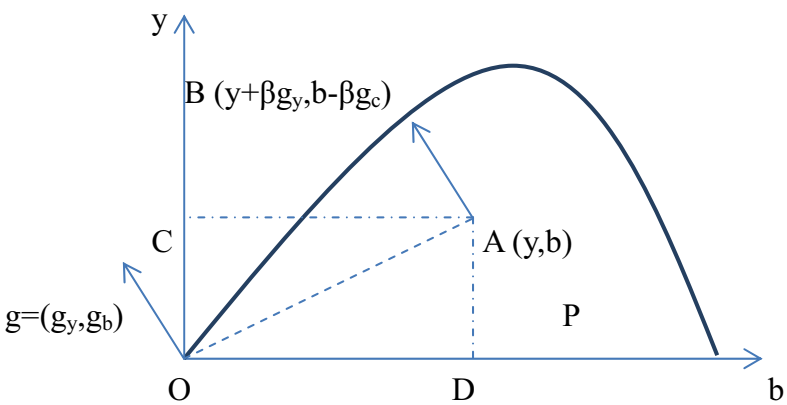

toward point $\mathrm{B}$, which not only reduces the undesirable output $\left(\mathrm{CO}_{2}\right.$ emission), but also increases the desirable output (GDP). Hence, the DDF is measured by $\beta=\mathrm{AB} / \mathrm{Og}$.

\subsection{Calculation of DDF}

Translog and the quadratic form of function are used to calculate the DDF. The translog form of function depicts a simultaneously proportionate transformation of desirable and undesirable output. The quadratic form of function depicts a transformation of the increase in the desirable output, while decreasing the undesirable output at the same time (Wei et al. 2013). Hence, the quadratic form is suitable for reality.

$$
\begin{aligned}
\vec{D}\left(x, y, b ; g_{y}, g_{b}\right)= & \alpha_{0}+\sum_{i=K, L, E} \alpha_{i} x_{i}+\alpha_{y} y+\alpha_{b} b+\frac{1}{2} \sum_{i=K, L, E j=K, L, E} \sum_{i j} x_{i} x_{j}+\frac{1}{2} \alpha_{y y} y^{2}+\frac{1}{2} \alpha_{b b} b^{2} \\
& +\sum_{i=K, L, E} \alpha_{i y} x_{i} y+\sum_{i=K, L, E} \alpha_{i b} x_{i} b+\sum_{i=K, L, E} \alpha_{i b} x_{i} b+\alpha_{y b} y b
\end{aligned}
$$

subject to:

$$
\begin{aligned}
& g_{y} \beta_{y}-g_{b} \gamma_{b}=-1 ; \\
& g_{y} \beta_{y y}-g_{b} \mu_{y b}=0 ; \\
& g_{y} \mu_{y b}-g_{b} \gamma_{b b}=0 ; \\
& g_{y} \sum_{i=K, L, E} \delta_{i}-g_{b} \sum_{i=K, L, E} \eta_{i}=0 ; \\
& g_{y}^{2} \beta_{y y}+g_{b}^{2} \gamma_{b b}-g_{y} g_{b} \mu_{y b}=0 ;
\end{aligned}
$$

where $\alpha_{0}, \alpha_{\mathrm{i}}, \alpha_{b}, \alpha_{i j}, \alpha_{y y}, \alpha_{b b}, \alpha_{i y}, \alpha_{i b}$ and $\alpha_{y b}$ are the coefficients of the DDF function. $\beta_{y}$, $\beta_{y y}, \gamma_{b}, \gamma_{b b}, \mu_{y b}, \delta_{i}$ and $\eta_{i}$ are the coefficients of the constrains of DDF function.

The DEA and LP methods are usually used to solve DDF. However, the production function form will distinctly affect the results (Zhou et al. 2015). Hence, the SFA method, which can manage random errors, was used to solve DDF in this paper.

The SFA method was proposed by Aigner et al. (1977). Färe et al. (2005) applied the SFA to DDF.

$$
\vec{D}_{0}\left(x_{n}, y_{n}, b_{n} ; g_{y},-g_{b}\right)+v^{n}-u^{n}=0
$$

where $v$ represents random noise (random error) and satisfies a normal distribution (i.e., $v^{n} \sim N\left(0, \sigma_{v}^{2}\right)$, and $u$ represents the inefficiency and satisfies a half-normal distribution (i.e., $u^{n} \sim N^{+}\left(0, \sigma_{n}^{2}\right)$. 
The revenue of a certain region can be defined as:

$$
R=p\left[y+\left(1-\vec{D}_{0}\right) g_{y}\right]-p_{b}\left[b+\left(1-\vec{D}_{0}\right) g_{b}\right]
$$

where $p$ represents the price of GDP $(p=1)$. $p_{b}$ represents the price of $\mathrm{CO}_{2}$ and indicates the MAC in this paper.

The MAC expressed by Eq. 7 after taking the partial derivation of $b$ and y on Eq. 6 is:

$$
p_{b}=\frac{\partial \vec{D}_{0}}{\partial b} \times \frac{\partial y}{\partial \vec{D}_{0}}
$$

Equation 3 is the first-order homogeneous equation, which contains desirable and undesirable outputs. To measure the MAC, the natural logarithm was taken as the normalization process on Eq. 3.

$$
\ln D_{0}=\ln \left(D_{0} / y\right)=\ln D_{0}-\ln y
$$

Hence,

$$
\begin{gathered}
-\ln y=\alpha_{0}+\alpha_{k} \ln x_{k}+\alpha_{l} \ln x_{l}+\alpha_{e} \ln x_{e}+\gamma_{b} \ln b+\frac{1}{2} \alpha_{k l} \ln x_{k} \ln x_{l}+\frac{1}{2} \alpha_{l e} \ln x_{l} \ln x_{e} \\
+\frac{1}{2} \alpha_{k e} \ln x_{k} \ln x_{e}+\frac{1}{2} \gamma_{b b}(\ln b)^{2}+\eta_{k} \ln x_{k} \ln b+\eta_{l} \ln x_{l} \ln b+\eta_{e} \ln x_{e} \ln b-\ln D_{0}
\end{gathered}
$$

Therefore, if $0<D_{0}<1$, then $\ln D_{0}<0$.

According to Eq. 4 and the numerical values of the inputs and outputs, the MAC can be expressed as:

$$
\begin{gathered}
p_{b}=-\frac{y}{b}\left(\frac{\partial \ln D_{0}}{\partial \ln b} / \frac{\partial \ln D_{0}}{\partial \ln y}\right) \\
=-\frac{y}{b}\left(\gamma_{b}+\gamma_{b b} \ln b+\eta_{k} \ln x_{k}+\eta_{l} \ln x_{l}+\eta_{e} \ln x_{e}\right)
\end{gathered}
$$

\subsection{Data}

\subsubsection{Data resources}

The inputs in this study included capital, labor and energy. The perpetual inventory method, which is proposed by Goldsmith in 1951, is generally accepted by previous studies to measure capital stoke. The perpetual inventory method was widely used in the measurement of Chinese capital stoke (e.g., Zhang et al. 2004; Shan 2008; Xiang and Ye 2011; Fan 2012). The labor and GDP were derived from the 2014 China Statistic Yearbook (CSY 2014), and the energy consumption was derived from the 2014 China Energy Statistic Yearbook (CESY 2014). Moreover, the energy consumption was estimated as standard coal by considering the standard coal coefficient. The $\mathrm{CO}_{2}$ emission was measured by the IPCC method.

\subsubsection{Measurement of $\mathrm{CO}_{2}$ emission}

The $\mathrm{CO}_{2}$ emission coefficient method is the most commonly used method to measure $\mathrm{CO}_{2}$ emissions. According to the IPCC 4th Climate Change Assessment Report, $90 \%$ of $\mathrm{CO}_{2}$ 
emissions came from the combustion of fossil fuels in developed countries. Fossil fuels are the main energy resource in undeveloped countries, like China. Therefore, the $\mathrm{CO}_{2}$ emissions from fossil fuels account for more than $90 \%$ in China (Diakoulaki and Mandaraka 2007).

Due to the specific application of energy resources from the 2014 China Energy Statistic Yearbook, seven energy resources were chosen to measure $\mathrm{CO}_{2}$ emissions: coal, coke, kerosene, gasoline, fuel oil, diesel and natural gas. Most crude oil is used to produce fuel oil and gasoline. Hence, crude oil was not taken into account in this study.

According to the 2006 IPCC Guidelines for National Greenhouse Gas Inventories (IPCC 2006), the $\mathrm{CO}_{2}$ emissions can be calculated by Eq. 11:

$$
C_{i}=E_{i j} \times \delta_{j}
$$

where $C_{\mathrm{i}}$ represents the $\mathrm{CO}_{2}$ emissions of province $i, E_{i j}$ represents the consumption of energy $j$ in province $\mathrm{I}$, and $\delta_{j}$ represents the coefficient of $\mathrm{CO}_{2}$ emissions of energy $j$.

The emission factors of energy resources were discussed in previous studies (e.g., Xu et al. 2006; Wang and Zhu 2008). The U.S. Department of Energy Information Administration, the Chinese Academy of Engineering, the Sustainable Development Strategy Research Group of the Chinese Academy of Sciences, the Energy Research Institute of the National Development and Reform Commission and the Institute of Policy and Management of the Chinese Academy of Sciences all measure the emission factors of energy. However, the different varieties of energy and carbon contents of energy caused mixed results.

The measurement of the $\mathrm{CO}_{2}$ emission factor proposed by the IPCC is shown by Eq. 12 .

$$
\delta_{j}=M_{j} \times \beta_{j} \times \varepsilon_{j} \times \omega
$$

where $M_{j}$ represents the net calorific value of energy $j, \beta_{j}$ represents carbon content of the unit heat value of energy $j$, and $\varepsilon_{j}$ represents the carbohydrate oxidation of energy $j . \omega$ represents the gasification coefficient of $\mathrm{CO}_{2}$ and has a constant value of 44/12. According to the standard coal coefficient, net calorific power, carbon content and oxygenation efficiency in the 2014 China Energy Statistic Yearbook and Eq. 11, the $\mathrm{CO}_{2}$ emission factors were measured (see Table 2).

By placing the energy consumption data and $\mathrm{CO}_{2}$ emission factors of each energy in Eq. 10, the $\mathrm{CO}_{2}$ emissions of Chinese provinces could be calculated.

\subsection{Measurement of $\mathrm{CO}_{2} \mathrm{MAC}$}

Table 3 shows the descriptive statistics of five variables.

Take the logarithm of variables to unify the dimension.

Table $2 \mathrm{CO}_{2}$ emission factors of energy unit: $\mathrm{kg}-\mathrm{CO}_{2} / \mathrm{kg}$

\begin{tabular}{llll}
\hline Energy & $\begin{array}{l}\mathrm{CO}_{2} \text { emission } \\
\text { factor }\end{array}$ & Energy & $\begin{array}{l}\mathrm{CO}_{2} \text { emission } \\
\text { factor }\end{array}$ \\
\hline Coal & 2.3816 & Fuel oil & 3.1704 \\
Coke & 2.8526 & Diesel oil & 3.0959 \\
Kerosene & 3.0333 & Natural gas & 2.1650 \\
Gasoline & 2.9250 & & \\
\hline
\end{tabular}


Table 3 Descriptive statistics of input and output variables

\begin{tabular}{lllccc}
\hline & $\begin{array}{l}\text { Capital } \\
\left(10^{9} \text { yuan }\right)\end{array}$ & $\begin{array}{l}\text { Labor } \\
\left(10^{5} \text { persons }\right)\end{array}$ & $\begin{array}{l}\text { Energy } \\
\left(10^{5} \text { TCE }\right)\end{array}$ & $\begin{array}{l}\text { GDP } \\
\left(10^{9} \text { yuan }\right)\end{array}$ & $\begin{array}{l}\mathrm{CO}_{2} \\
\left(10^{5} \text { ton }\right)\end{array}$ \\
\hline Mean & 23898.26 & 4506.8 & 86358.48 & 20973.39 & 1610511 \\
Maximum & 58895.16 & 10644 & 210072.1 & 62163.97 & 4295983 \\
Minimum & 4443.382 & 578 & 13300.89 & 2101.05 & 143943.6 \\
\hline
\end{tabular}

Table 4 DDF's coefficient

\begin{tabular}{lrrr}
\hline Coefficient & Value & Coefficient & Value \\
\hline$r_{\mathrm{b}}$ & -0.038 & $\eta_{1}$ & -0.019 \\
$r_{\mathrm{bb}}$ & 0.068 & $\eta_{\mathrm{e}}$ & 0.008 \\
$\eta_{\mathrm{k}}$ & -0.031 & & \\
\hline
\end{tabular}

The DDF's coefficient was calculated by using the $\mathrm{CO}_{2}$ emission values in Eq. 10 and the Fronter4.1 software (see Table 4).

The $\mathrm{CO}_{2}$ MACs of Chinese provinces can be measured by Eq. 10 .

\section{Results and discussion}

\subsection{Results}

\subsection{1 $\mathrm{CO}_{2}$ emissions}

According to Fig. 2, the $\mathrm{CO}_{2}$ emissions of Chinese provinces differed drastically. The large $\mathrm{CO}_{2}$ emitters, like Shandong Province, Hebei Province and Inner Mongolia, were provinces with flourishing industries. The small $\mathrm{CO}_{2}$ emitters were classified into two groups. Beijing City and Tianjin City had small territories and well-developed tertiary industries. Provinces which are less developed like Ningxia Province, Gansu province and Qinghai Province were also small emitters.

\subsubsection{MAC}

In this paper, we used DEA and SFA methods to calculate the 30 provinces' carbon dioxide MAC in 2013. Fronter4.1 and Deap2.1 softwares are used.

According to Fig. 3, the MACs of Chinese provinces differed exceedingly. The calculation results of the SFA method were as follows. The eastern provinces, like Beijing and Shanghai, had high MACs, while the western and southern provinces, like Guizhou and Gansu, had low MACs. Provinces with affluent industries, like Shanxi and Inner Mongolia, also had low MACs. The results of the DEA method shows that Beijing, Shanghai, Guangdong and Tianjin have over 200 yuan/ton MACs and the MAC value of Inner Mongolia and Ningxia is 0 .

The average result of the MAC calculated by the SFA method was $55 \%$ lower than the DEA method. 
$\mathrm{CO}_{2}$ emission in 2013

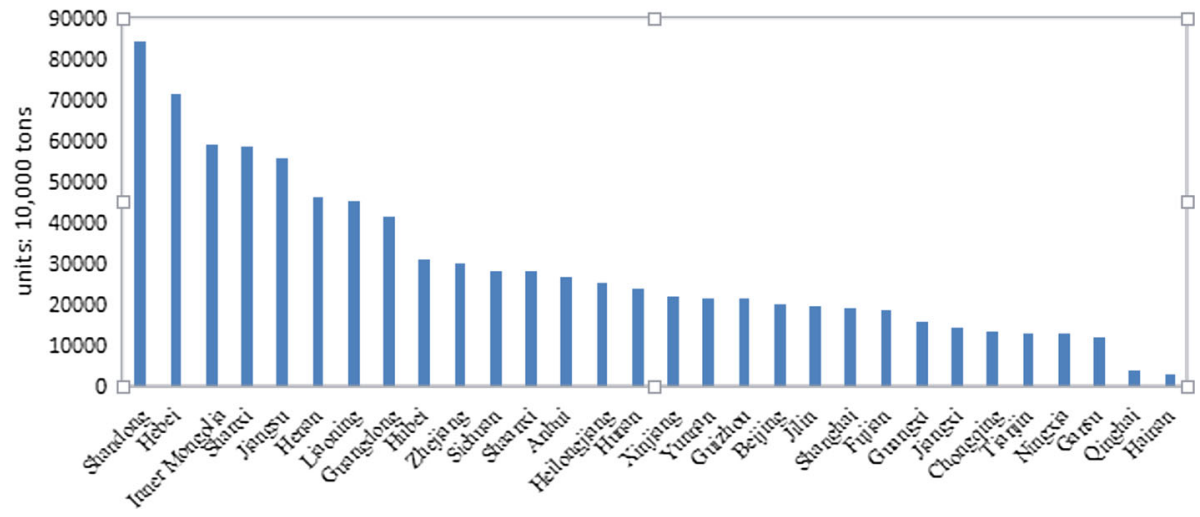

Fig. $2 \mathrm{CO}_{2}$ emission of Chinese provinces in 2013 (units: 10 thousand tons)

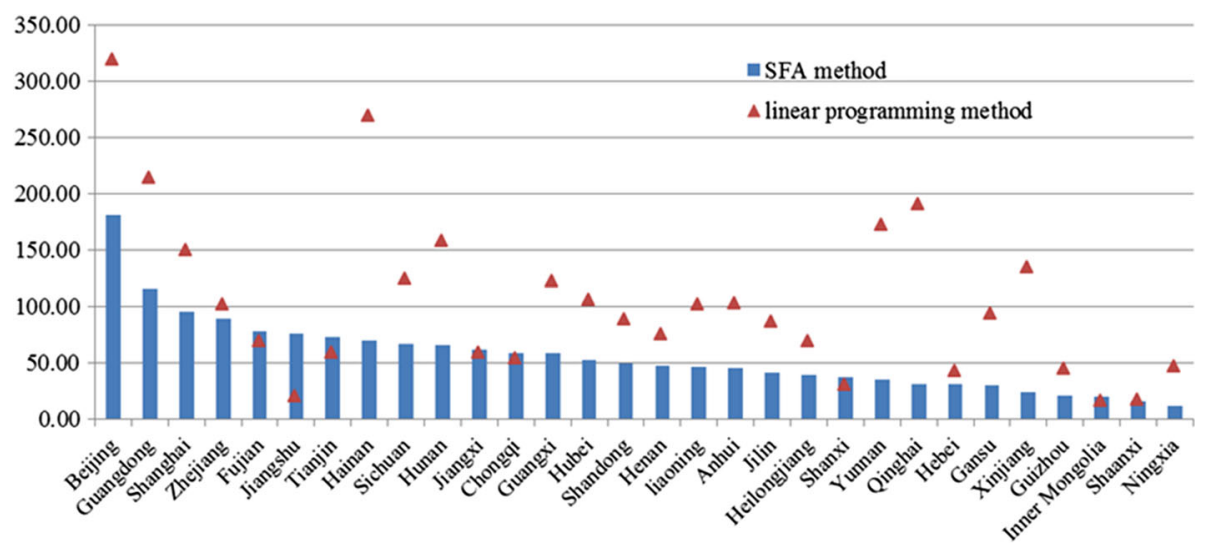

Fig. $3 \mathrm{CO}_{2}$ MAC of Chinese provinces in 2013 using the SFA and DEA methods (units: yuan/ton)

\subsection{Discussion}

\subsubsection{Comparison between SFA and DEA methods}

SPSS 21.0 software was used to conduct Spearman test and paired sample $T$ test. Figure 4 shows the correlation coefficient in Spearman test is 0.818 which means the ranking order of MAC results of SFA and DEA methods is highly related. The MAC ranking order of most of the provinces is stable except Heilongjiang, Shandong, Henan and Sichuan. Heilongjiang and Shandong have huge $\mathrm{CO}_{2}$ output. Henan and Sichuan have large energy input. Besides, the capital input in Sichuan is also high. The large difference between inputs and outputs will lead to different production frontier, and the MAC ranking order will be different. 
Correlations

\begin{tabular}{|lll|r|r|}
\hline & & \multicolumn{1}{c|}{ SFA } & \multicolumn{1}{c|}{ DEA } \\
\hline Spearman's rho & SFA & Correlation Coefficient & 1.000 & $.818^{\mathrm{xx}}$ \\
& & Sig. (2-tailed) & & .000 \\
& $\mathrm{~N}$ & 30 & 30 \\
\cline { 2 - 5 } & DEA & Correlation Coefficient & $.818^{\mathrm{xx}}$ & 1.000 \\
& Sig. (2-tailed) & .000 & \\
& $\mathrm{~N}$ & 30 & 30 \\
\hline
\end{tabular}

$\star$ Correlation is significant at the 0.01 level (2-tailed).

Fig. 4 Spearman test correlations

Figure 5 shows the basic information of MAC sequence calculated by SFA and DEA. The mean value, standard deviation and the standard error mean of SFA sequence were lower than those of DEA sequence. So the SFA sequence is more stable than DEA sequence.

Figure 6 shows the absolute value of paired sample $T$ test is 7.182 and it is higher than the critical value when the degree of freedom is 29 . Hence, the value of SFA and DEA sequence has significant difference.

\subsubsection{Reliability test of the SFA result}

Fronter4.1 software was used to measure the coefficient of DDF. The result showed that $\gamma^{2}=\sigma_{u}^{2} / \sigma^{2}=0.5$. The result of $\mathrm{r}$ represents that half of the error was caused by random errors. Hence, the SFA method is appropriate in this paper.

Meanwhile, the coefficient of Eq. 10, standard deviation and statistical tests at $1 \%$ significance are shown in Table 5.

The critical value of $19^{\circ}$ of freedom was 1.729 , as determined from the critical value table of the $t$ test. The absolute value of the $t$ ratio value in Table 4 was greater than the critical value, which meant that the $t$ test of coefficient was significant and the coefficient result was reliable.

Our calculation results of the average carbon dioxide MAC of those provinces are $55 \%$ less than the previous calculations, so from the economic point of view, the national $\mathrm{CO}_{2}$ emission reduction target of $40-45 \%$ is feasible.

\subsubsection{Influence factor analysis of MAC}

The composition of $\mathrm{CO}_{2}$ emissions and the comparison between $\mathrm{CO}_{2}$ emission and MACs are shown in Figs. 7 and 8, respectively.

Paired Samples Statistics

\begin{tabular}{|c|c|c|c|c|c|}
\hline & & Mean & $\mathrm{N}$ & Std. Deviation & $\begin{array}{l}\text { Std. Error } \\
\text { Mean }\end{array}$ \\
\hline \multirow[t]{2}{*}{ Pair 1} & SFA & 56.0246 & 30 & 34.28932 & 6.26034 \\
\hline & DEA & 125.5333 & 30 & 77.24155 & 14.10231 \\
\hline
\end{tabular}

Fig. 5 Basic information of MAC sequence calculated by SFA and DEA 
Paired Samples Test

\begin{tabular}{|c|c|c|c|c|c|c|c|c|c|}
\hline & \multicolumn{5}{|c|}{ Paired Differences } & \multirow[b]{3}{*}{$t$} & \multirow[b]{3}{*}{$d f$} & \multirow[b]{3}{*}{ Sig. (2-tailed) } \\
\hline & & \multirow[b]{2}{*}{ Mean } & \multirow[b]{2}{*}{ Std. Deviation } & \multirow[b]{2}{*}{$\begin{array}{l}\text { Std. Error } \\
\text { Mean }\end{array}$} & \multicolumn{2}{|c|}{$\begin{array}{c}95 \% \text { Confidence Interval of the } \\
\text { Difference }\end{array}$} & & & \\
\hline & & & & & Lower & Upper & & & \\
\hline Pair1 & SFA-DEA & -69.50872 & 53.01005 & 9.67827 & .89 .30300 & -49.71444 & -7.182 & 29 & .000 \\
\hline
\end{tabular}

Fig. 6 Paired sample test value

Table 5 Coefficient of DDF, standard deviation and $\mathrm{t}$ ratio

\begin{tabular}{lrlr}
\hline Coefficient & Coefficient value & Standard deviation & T ratio \\
\hline$r_{\mathrm{b}}$ & -0.038 & 2.682 & -1.825 \\
$r_{\mathrm{bb}}$ & 0.068 & 2.041 & 3.376 \\
$\eta_{\mathrm{k}}$ & -0.031 & 1.374 & -2.319 \\
$\eta_{1}$ & -0.019 & 1.298 & -1.923 \\
$\eta_{\mathrm{e}}$ & 0.008 & 1.147 & -7.082 \\
\hline
\end{tabular}

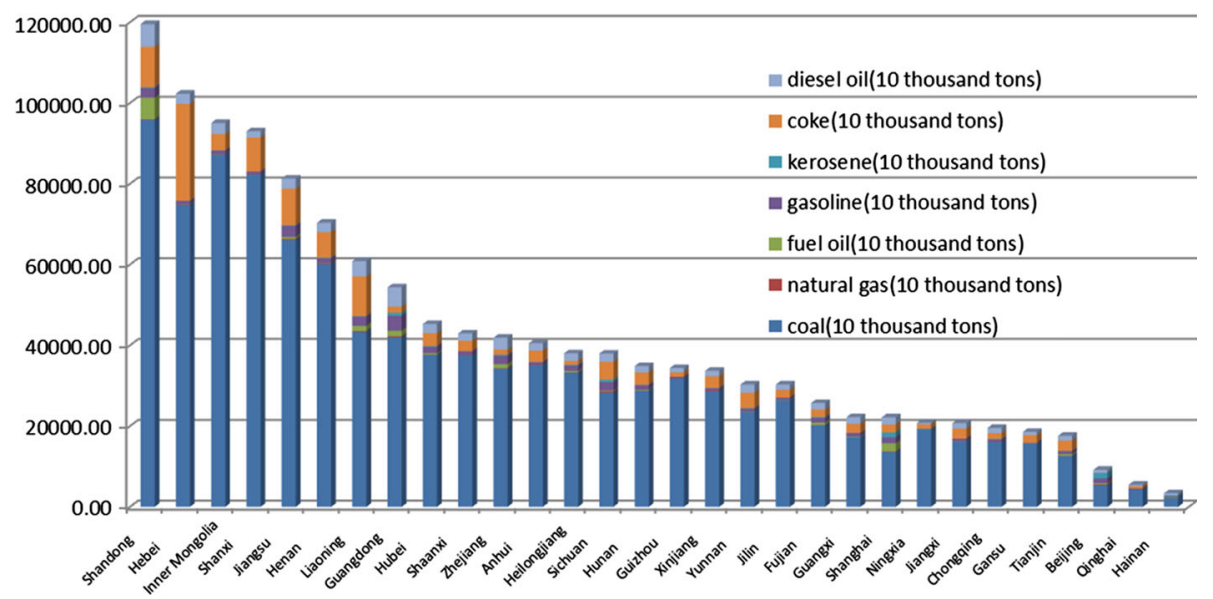

Fig. $7 \mathrm{CO}_{2}$ emissions of Chinese provinces in 2012

In general, there were no distinct correlations between the $\mathrm{CO}_{2}$ emissions and MACs of the Chinese provinces. Industrial structures, energy consumption structures and natural resources were the factors that influenced the $\mathrm{CO}_{2}$ emissions and MACs of Chinese provinces.

(1) Industrial structures

Figure 7 shows that large $\mathrm{CO}_{2}$ emitters like Shandong, Hebei, Shanxi and Inner Mongolia were highly developed industry provinces. According to the 2013 China Statistic Yearbook (CSY 2014), the ratios of the secondary industries of large emitters were more than $50 \%$. High-carbon secondary industries, such as the steel industry and mining industry, were the leading industries in those large emitters. Hence, the MACs of large emitters were low. Small emitters were divided into two groups. The first group consisted of provinces with highly developed, but low-carbon tertiary industries, such as the financial industry, wholesale and retail trade industry and catering accommodation industry. Beijing, 


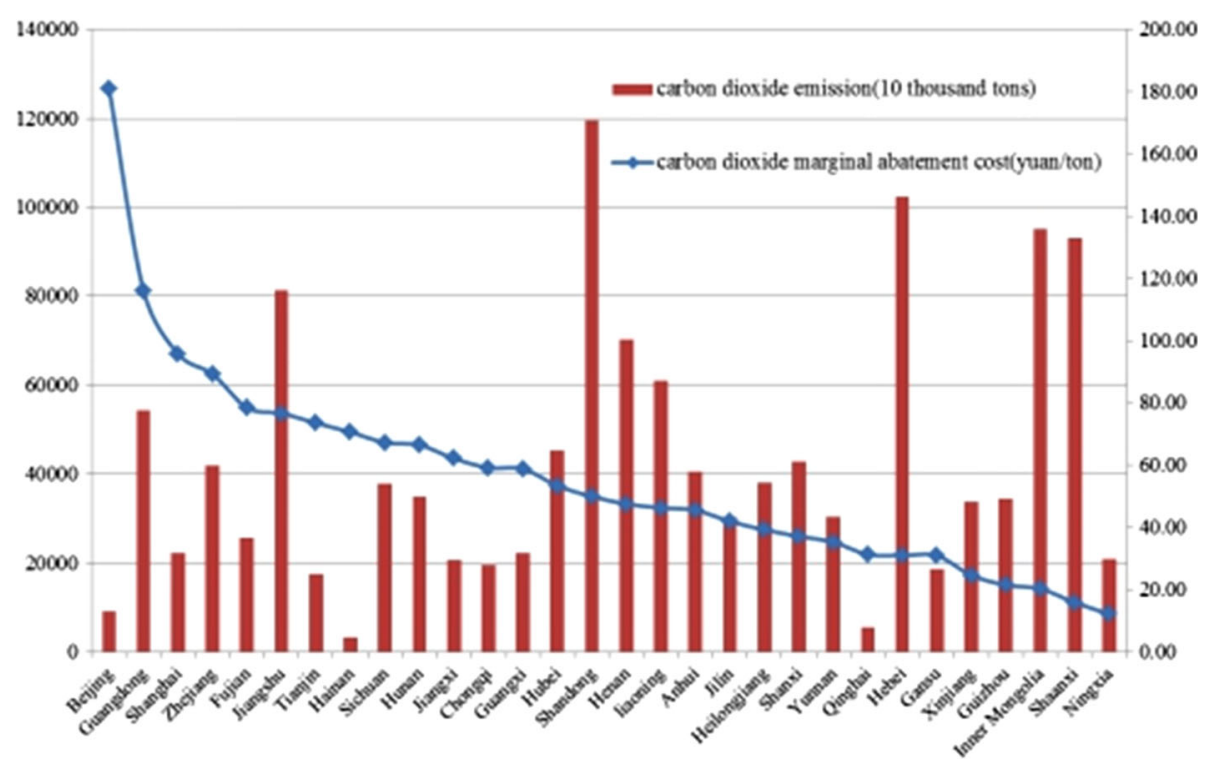

Fig. 8 Comparison between $\mathrm{CO}_{2}$ emission and MAC of Chinese provinces

Tianjin, Shanghai and Hainan were in the first group. The ratios of the low-carbon industries in those provinces were more than half of the total ratio of the tertiary industries. Low-carbon industries emit little $\mathrm{CO}_{2}$, and it would be a large economic loss to reduce $\mathrm{CO}_{2}$ emission. Therefore, the MACs of the first group of small emitters were low. The other group of small emitters included western provinces, like Ningxia, Gansu and Qinghai, with rising new energy industries. However, there were still metallurgy industries with large $\mathrm{CO}_{2}$ emissions in those provinces. Hence, with relatively small $\mathrm{CO}_{2}$ emissions, the MACs of the second group of provinces were low.

(2) Energy consumption structures

Coal was the main emitter of $\mathrm{CO}_{2}$ emissions in the whole country (see Fig. 7). The average ratio of the $\mathrm{CO}_{2}$ emissions from the coal combustion of 30 Chinese provinces was $80 \%$. Coal was mainly used for power generation, the production of building materials and domestic use. Moreover, coke, mainly used in metal smelting, had the second large $\mathrm{CO}_{2}$ emission. Hebei Province, one of the largest steel provinces in China, consumed a large amount of coke for metal smelting, with $23 \%$ of the $\mathrm{CO}_{2}$ emissions coming from coke. Diesel oil was mainly used as fuel for large vehicles and vessels. Gasoline was the fuel for compact cars. The blossoming trade and large demand for transportation in Shanghai, Guangdong and Zhejiang consumed large amounts of diesel oil and gasoline. Small amounts of kerosene and fuel oil were consumed, and natural gas is a relatively clean energy. The $\mathrm{CO}_{2}$ emissions from these three energies were low. It is easier to reduce high-carbon energy's $\mathrm{CO}_{2}$ emission. Therefore, the MACs of Hebei Province and Shandong Province were low, while Beijing and Shanghai were high.

(3) Natural resources

Southern provinces, such as Hubei, Sichuan and Yunnan provinces, had abundant hydropower. The ratios of hydropower in Hubei, Sichuan and Yunnan provinces among all provinces were 16, 17 and $14 \%$ in 2013, respectively. Inner Mongolia, Hebei and Liaoning provinces had affluent wind power resources, and the ratios of installed capacity 
of wind-driven power among all provinces were 35, 10 and $9 \%$, respectively (2014 China Energy Statistic Yearbook). Hydropower and wind power are clean energy and will not produce $\mathrm{CO}_{2}$ emissions. Hence, the MACs of the above-mentioned provinces were high.

\section{Conclusion and the policy suggestions}

\subsection{Conclusion}

(1) As SFA method can distinguish the random error from inefficiency, the MAC results were more precise than DEA method. But SFA MAC average results were $55 \%$ less than the DEA method's results in this study as random errors were taken into account. So from the economic point of view, the national $\mathrm{CO}_{2}$ emission reduction of $40-45 \%$ is feasible.

(2) The ranking order MAC results sequence of SFA method and DEA method is highly correlated. But the MAC value of SFA and DEA methods has significant difference.

(3) There were no distinct correlations between $\mathrm{CO}_{2}$ emissions and MACs.

(4) The $\mathrm{CO}_{2}$ emissions and MACs of each province varied, due to the different industrial structures, energy consumption structures and natural resources among Chinese provinces.

\subsection{Policy suggestions}

According to the results of this study, MAC of each province is substantially different. Hence, the central government should formulate a fair $\mathrm{CO}_{2}$ emission reduction principle considering the MAC, the different industrial structure and the level of economic of each province. Two suggestions are made as follows:

\subsubsection{Formulate $\mathrm{CO}_{2}$ emission reduction targets principle based on MAC and affordability of the local economy}

The MAC and the affordability of the local economy should be considered when allocating the annual $\mathrm{CO}_{2}$ emission reduction target of each province. On the other hand, the central government should highlight the leading role of the developed provinces. Each province has different MAC due to the different industry structure and leading industry in the province. The major industries of less developed provinces are mostly high $\mathrm{CO}_{2}$ emission and low value-added secondary industries such as thermal power, steel and chemical industries. The MAC of those provinces is relatively lower, and their $\mathrm{CO}_{2}$ emission reduction is easier. The developed provinces, on the contrary, have high economic development level and high value-added tertiary industries. The MAC of developed provinces is high, and their $\mathrm{CO} 2$ emission reduction is more challenging.

Therefore, the central government should first ensure the accomplishment of the total $\mathrm{CO}_{2}$ emission reduction task and demonstrate the $\mathrm{CO}_{2}$ emission reduction determination. Based on the principle that lower MAC reduces more $\mathrm{CO}_{2}$ emissions and higher MAC reduces less, the annual $\mathrm{CO}_{2}$ emission reduction targets of each provinces can then be determined by reasonably increasing the targets in lower MAC provinces and appropriately decreasing the targets in higher MAC ones. Furthermore, as the developed provinces with high MAC reduce less $\mathrm{CO} 2$ emissions, a feedback mechanism in which developed 
provinces compensate developing provinces should be established. Finally, the leading role of developed provinces in $\mathrm{CO}_{2}$ emission reduction should be established, while industrial structure transformation and tertiary industry developing should be encouraged in developing provinces.

\subsection{2 $\mathrm{CO}_{2}$ emission reduction targets should consider natural resource endowments and embodied carbon transfer}

When determining the annual emission reduction targets, the central government should establish a corresponding subsidy mechanism in accordance with the supply and demand of raw material and energy between the provinces. The transportation of raw material and energy between provinces will result in embodied carbon transfer. $\mathrm{CO}_{2}$ emission reduction target should consider the natural resource endowment and raw material and energy import/export situation. A subsidy mechanism should be established to compensate raw material and energy output provinces to ensure that the emission reduction targets of the provinces are fair and reasonable.

Acknowledgments The authors would like to thank the anonymous reviewers and editors for their valuable suggestions. The authors express thanks for the support from the development research center of China Geological Survey Bureau under Grant Nos. 1212011220303 and 12120114056601, the Chinese Academy of Land and Resource Economics under Grant No. 12120113093200 and the Fundamental Research Funds for the Central Universities under Grant No.53200859550. The authors would like to express their gratitude to Professor Di Zhou, Professor Jingyan Fu who provided valuable suggestions.

Open Access This article is distributed under the terms of the Creative Commons Attribution 4.0 International License (http://creativecommons.org/licenses/by/4.0/), which permits unrestricted use, distribution, and reproduction in any medium, provided you give appropriate credit to the original author(s) and the source, provide a link to the Creative Commons license, and indicate if changes were made.

\section{References}

Aigner DJ, Lovell CK, Schmidt P (1977) Formulation and estimation of stochastic frontier production function models. J Econ 6(1):21-37

Aparicio J, Pastor TJ, Vidal F (2016) The directional distance function and the translation invariance property. Omega 58:1-3

Ba SS, W DY (2010) Empirical evidence of the relation among energy consumption, carbon dioxide emissions and economic growth based on the abatement costs, research on economics and management, 6:5-11 (in Chinese)

CESY, China Energy Statistical Yearbook (2014) National Bureau of Statistics of China

Chambers RG, Chung Y, Färe R (1996) Benefit and distance functions. J Econ Theory 70:407-419

Chang N (2014) Changing industrial structure to reduce carbon dioxide emissions: a Chinese application. J Clean Prod 103:40-48

Chen WY (2005) The costs of mitigating carbon emissions in China: findings from China MARKALMACRO modeling. Energy Policy 33:885-896

Chen SY (2010) Industrial carbon dioxide shadow price: parametric and non-parametric methods. J World Econ 8:93-111 (in Chinese)

Chen WY (2011) The potential role of CCS to mitigate carbon emissions in future China. Energy Procedia 4:6007-6014

Chen SY (2013) What is the potential impact of a taxation system reform on carbon abatement and industrial growth in China? Econ Syst 37(3):369-386

Chen WY, Wu ZX, He JK, Gao PF, Xu SF (2007) Carbon emissions control strategies for China: a comparative study with partial and general equilibrium versions of the China MARKAL model. Energy 32:59-72 
China Electricity Council, China's carbon dioxide emissions accounted for about $23 \%$ of the world's proportion [EB/OL],http://www.cec.org.cn/xinwenpingxi/2011-12-07/75372.html. Accessed 09 Dec 2015

China.com. Grey elephant in the room after all east flow to them- Documentary of Premier Wen Jiabao at the Copenhagen Climate Change Conference [EB/OL] http://www.china.com.cn/international/txt/ 2009-12/25/content_19131245_2.htm. Accessed 05 May 2015

Choi Y, Zhang N, Zhou P (2012) Efficiency and abatement costs of energy-related CO2 emissions in China: a slacks-based efficiency measure. Appl Energy 98:198-208

CSY, China Statistical Yearbook (2014) National Bureau of Statistics of China

Diakoulaki D, Mandaraka M (2007) Decomposition analysis for assessing the progress in decoupling industrial growth from CO2 emissions in the EU manufacturing sector. Energy Econ 29(4):636-664

Dou YM, Li FY (2012) Shadow price of environmental pollutants: a newly parametric measure method, Statistic and Decision, No.19, 32-35 (in Chinese)

Du LM, Mao J (2015) Estimating the environmental efficiency and marginal CO2 abatement cost of coalfired power plants in China. Energy Policy 85:347-356

Fan Y (2011) Greenhouse gas emission reduction cost, path and policy research. Science Press, Beijing (in Chinese)

Fan Q (2012) Details of perpetual inventory method and capital stock estimation of China from 1952 to 2009. J Yunnan Univ Finance Econ 3:42-50 (in Chinese)

Fan Y, Zhang XB, Zhu L (2010) Estimating the macroeconomic cost of CO2 emissions abatement in China based on multi-objective programming. Adv Clim Change Res 2:130-135 (in Chinese)

Färe R, Grosskopf S, Lovell CAK, Suthathip Y (1993) Derivation of shadow prices for undesirable outputs: a distance function approach. Rev Econ Stat 75(2):374-380

Färe R, Grosskopf S, Noh DW, Weber W (2005) Characteristics of a polluting technology: theory and practice. J Econ 126(2):469-492

Gao PF, Chen WY, He JK (2004) Marginal abatement cost in China. J Tsinghua Univ (Sci Technol) 44(9):1192-1195 (in Chinese)

Garg A, Shukla PR, Maheshwari J, Upadhyay J (2014) An assessment of household electricity load curves and corresponding $\mathrm{CO} 2$ marginal abatement cost curves for Gujarat state, India. Energy Policy 66:568-584

Gómez-Calvet R, Conesa D, Gómez-Calvet AR, Tortosa-Ausina E (2014) Energy efficiency in the European Union: what can be learned from the joint application of directional distance functions and slacksbased measures? Appl Energy 132:137-154

Guo YQ, JY Zheng, Ge QS (2010) Study on the primary energy-related carbon dioxide emissions in China. Geogr Res 29(6):1027-1036 (in Chinese)

Hailu A, Veeman TS (2000) Environmentally sensitive productivity analysis of the Canadian Pulp and paper industry 1959-1994: an input distance function approach. J Environ Econ Manag 40(3):251-274

He XP (2015) Regional differences in China's CO2 abatement cost. Energy Policy 80:145-152

Ipcc.ch. The 2006 IPCC country listing guidelines of greenhouse gases [EB/OL]. http://www.ipcc-nggip. iges.or.jp/public/2006gl/chinese/. Accessed 31 Aug 2015

Ko FK, Huang CB, Yseng PY, Lin CH, Zheng BY, Chiu H (2010) Long term CO2 emissions reduction target and scenarios of power sector in Taiwan. Energy Policy 38:288-300

Lee M (2005) The shadow price of substitutable sulfur in the US electric power plant: a distance function approach. J Environ Manag 77(2):104-110

Lee M, Zhang N (2012) Technical efficiency, shadow price of carbon dioxide emissions, and substitutability for energy in the Chinese manufacturing industries. Energy Econ 34:1492-1497

Lee JD, Park JB, Kim TY (2002) Estimation of the shadow prices of pollutants with production/environment inefficiency taken into account: a nonparametric directional distance function approach. J Environ Manag 64(4):365-375

Li T, Chen LJ, Fan Y (2010) Empirical study for CO2 abatement allocation among provinces in China: based on a nonlinear programming model. Manag Rev 22(6):54-60 (in Chinese)

Liao H, Wei YM (2011) China's energy and CO2 emission forecasting and perspective in the 12th FiveYear Plan. Bull Chin Acad Sci 26(2):150-153 (in Chinese)

Liu ML, Zhu L, Fan Y (2011) Evaluation of carbon emission performance and estimation of marginal CO2 abatement costs for provinces of China: a non-parametric distance function approach. China Soft Sci 3:106-114 (in Chinese)

Matsushita K, Yamane F (2012) Pollution from the electric power sector in Japan and efficient pollution reduction. Energy Econ 34:1124-1130

Molinos-Senante M, Hanley N, Sala-Garrido R (2015) Measuring the CO2 shadow price for wastewater treatment: a directional distance function approach. Appl Energy 144:241-249 
Qi TY, Niven W, Valerie JK, Zhang XL (2014) Will economic restructuring in China reduce tradeembodied CO2 emissions? Energy Econ 42:204-212

Qin SJ, Zhang WK, Yin HT (2011) Cost of CO2 emission reduction of conventional thermal power plants in Shanghai-An estimation based on output distance function. J Eng Manag 25(6):704-708 (in Chinese)

Rezek JP, Campbell RC (2007) Cost estimates for multiple pollutants: a maximum entropy approach. Energy Econ 29(3):503-519

Shan HJ (2008) Re-estimating the capital stock of China: 1952-2006. J Quant Tech Econ 10:17-31 (in Chinese)

Shephard RW (1970) Theory of cost and production function[M]. New Jersey Princeton University Press, Princeton

Song JK (2010) Effect factors of China's carbon dioxide emission and the carbon dioxide reduction measures analysis, Price: Theory and Practice, 1: 37-38 (in Chinese)

Tu ZG (2009) The shadow price of industrial SO2 emission: a new analytic framework. China Econ Quart 9(1):259-282 (in Chinese)

Vardanyan M, Noh D (2006) Approximating pollution abatement costs via alternative specifications of a multi-output production technology: a case of the US electric utility industry. J Environ Manag 80(2):177-190

Wang K, Wei YM (2014) China's regional industrial energy efficiency and carbon emissions abatement costs. Appl Energy 130:617-631

Wang Z, Zhu YB (2008) Study on the Status of carbon emission in provincial scale of China and countermeasures for reducing its emission. Bull Chin Acad Sci 23(2):109-115 (in Chinese)

Wang K, Wang C, Lu XD, Chen JN (2007) Scenario analysis on CO2 emissions reduction potential in China's iron and steel industry. Energy Policy 35:2320-2335

Wang QW, Cui QJ, Zhou DQ, Wang SS (2011a) Marginal abatement costs of carbon dioxide in China: a nonparametric analysis. Energy Procedia 5:2316-2320

Wang X, Li JF, Zhang YX (2011b) An analysis on the short-term sectoral competitiveness impact of carbon tax in China. Energy Policy 39:4144-4152

Wang HL, Lu JP, Bai J (2014a) Shadow prices and pollution costs in Chinese agriculture. Jilin Univ J Soc Sci Edn 54(5):40-48 (in Chinese)

Wang W, Frank K, Dali RN, Pete S, Eli S, Ju XT, Guo LP, Han GD, de Perthuis C, Lin E, Moran D (2014b) Greenhouse gas mitigation in Chinese agriculture: distinguishing technical and economic potentials. Glob Environ Chang 26:53-62

Wei C, Löschel A, Liu B (2013) An empirical analysis of the CO2 shadow price in Chinese thermal power enterprises. Energy Econ 40:22-31

Wen YC, Wu YZ, (2011) Evaluation of Carbon Emission Performance and Estimation of Marginal $\mathrm{CO}_{2}$ Abatement Costs for Chinese Industrial Sector. In: International conference on information, services and management engineering (ISME2011), scientific research, 1782-1785

Wenruo H, Chu W (2012) An analysis of shadow price of carbon dioxide in China: based on a regional perspective. J Poyang Lake 2:70-78 (in Chinese)

Xiang RM, Ye F (2011) On the two approaches and their comparison on capital stocks based on perpetual inventory method. Stat Inf Forum 26(3):20-26 (in Chinese)

$\mathrm{Xu}$ YZ, Dong LL (2011) How to achieve double wins of carbon dioxide emissions and economic development-The positive analysis under the view of optimizing the energy structure, Journal of China University of Geosciences (Social Sciences Edition), 11(6): 31-37 (in Chinese)

$\mathrm{Xu}$ B, Lin BQ (2015) Carbon dioxide emissions reduction in China's transport sector: a dynamic VAR approach. Energy 83:486-495

Xu GQ, Liu ZY, Jiang ZH (2006) Decomposition model and empirical study of carbon emissions for China: 1995-2004. China Popul Resour Environ 16(6):158-161 (in Chinese)

Yuan P, Liang WB, Cheng S (2012) The margin abatement costs of CO2 in Chinese industrial sectors. Energy Procedia 14:1792-1797

Zhang N, Choi Y (2014) A note on the evolution of directional distance function and its development in energy and environmental studies 1997-2013. Renew Sustain Energy Rev 33:50-59

Zhang J, Wu GY, Zhang JP (2004) The estimation of China's provincial capital stock: 1952-2000, Economic Research Journal, No.10, 35-44 (in Chinese)

Zhang XP, Xu QN, Zhang F, Guo ZQ, Rao R (2014) Exploring shadow price of carbon emissions at provincial levels in China. Ecol Ind 46:407-414

Zhou P, Ang BW, Han JY (2010) Total factor carbon emission performance: a Malmquist index analysis. Energy Economics 32(1):194-201

Zhou X, Fan LW, Zhou P (2015) Marginal CO2 abatement costs: findings from alternative shadow price estimates for Shanghai Industrial sectors. Energy Policy 77:109-117 